\title{
The geomorphic characteristics of the Minshan Tectonic Belt along the northeast margin of the Tibetan Plateau — A DEM study
}

\author{
Hui ping Zhang†*, Nong Yangł and Shao feng Liu† \\ † School of Earth Sciences and Resources, China University of Geosciences (CUGB), Beijing, PO Box 100083, CHINA \\ ¥ Institute of Geomechanics, Chinese Acadamy of Gelogical Sciences (CAGS), CHINA
}

*To whom correspondence should be addressed.E-mail: beijingzhhuiping@163.com

Topographically, the eastern Tibetan Plateau with high elevation and thick crust is bounded by Longmenshan and Minshan Ranges (Deng et al. 1994, Zhao et al. 1994a, Searle 2001), and is one of the world's most remarkable continental escarpments (Kirby et al. 2002). The topographic elevations decreased gradually from $5000-6000 \mathrm{~m}$ in the northeast Tibetan Plateau to $600 \mathrm{~m}$ in the Sichuan Basin across a horizontal distance of only 50-60 km (Zhao et al. 1994, Searle 2001, Kirby et al. 2002). Moreover, the topographic expression of the eastern margin of the Tibetan Plateau is largely more irregular and diffuse in contrast to the northern and southern margins (Kirby et al. 2002).

The Minshan Tectonic Belt (MTB), first brought forward by Deng et al. (1994), is located in the northeast margin of the Tibetan Plateau (Figure 1). Tectonically and geomorphically, the MTB is the right linkage between the West Qinling, the Sichuan Basin and the Tibetan Plateau. The significant faults, the Longmenshan Thrust Belt (LTB), the Minjiang Fault Zone (MFZ), the Huya Fault (HF), and important contacts are shown in Figure 1. The Triassic sandstone and slate located in the western flank of the MFZ and the HF are in lower erodibility compared with the pre-Mesozoic carbonatite on the east side. Mostly influenced by the Cenozoic collision of India and Eurasia (Deng et al. 1994, Kirby 2000), the MTB experienced intense uplifting and erosion. The previous researches mostly dealt with the tectonic evolution and geomorphic characteristics of the LTB and the MFZ (Chen et al. 1994a, 1994b, 1994c, Deng et al. 1994, Zhao et al. 1994a, 1994b, Burchfiel et al. 1995, Chen andWilson 1996), and presented many theoretic and conceptual models of the geological evolution (Chen et al. 1994b, 1994c, Deng et al. 1994). But their studies have not dealt with the general geomorphic characteristics of the MTB as a whole. Combining with Quaternary deformation information and thermochronology data such as ${ }^{40} \mathrm{Ar} /{ }^{39} \mathrm{Ar}$, (U-Th)/He and FT, Dennis et al. (1994) and Kirby et al. (2000, 2002) systematically analyzed the neotectonics of the eastern margin of the Tibetan Plateau, and pointed out markedly heterogeneous denudation in late Cenozoic along the northeastern margin and the differential cooling evolution. According to the derformity style, stratigraphy distribution and geomorphic zonation, Yang et al. (2004, in press) proposed that the MTB comprises an uplifting zone clamped by two fault zones (Minjiang Fault and Huya Fault)

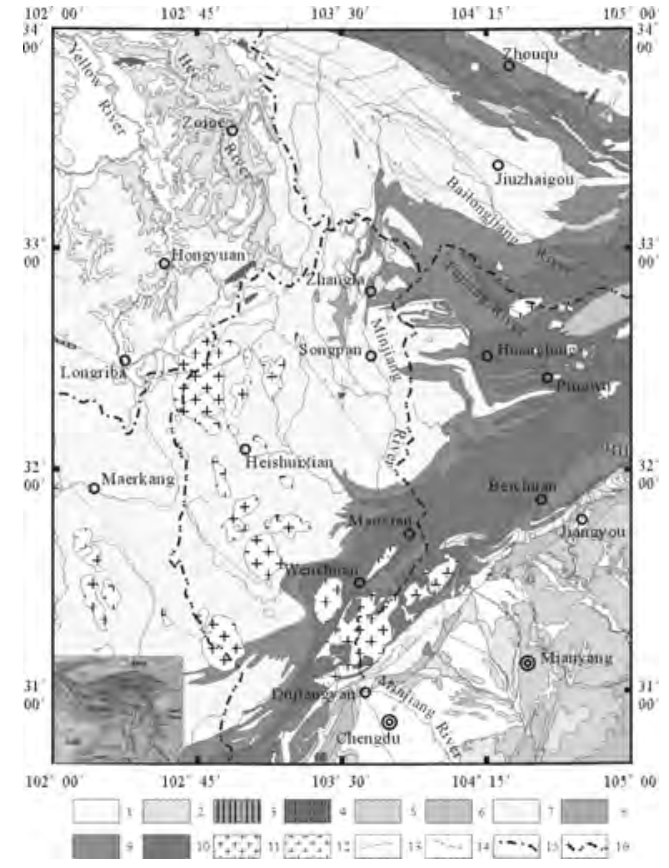

FIGURE 1. Simplified geological map of the MTB

1. Holocene, 2. Pleistocene, 3. Neocene, 4. Palaeogene, 5. Cretaceous, 6. J urassic, 7. Triassic, 8. Permian-Triassic, 9. Paleozoic, 10. PrePaleozoic, 11. Mesozoic granite 12. Mesozoic and Paleozoic diorite, 13. Fault, 14. Reverse fault, 15. Main drainage divide, 16. Secondary drainage divides. See text for the further discussion

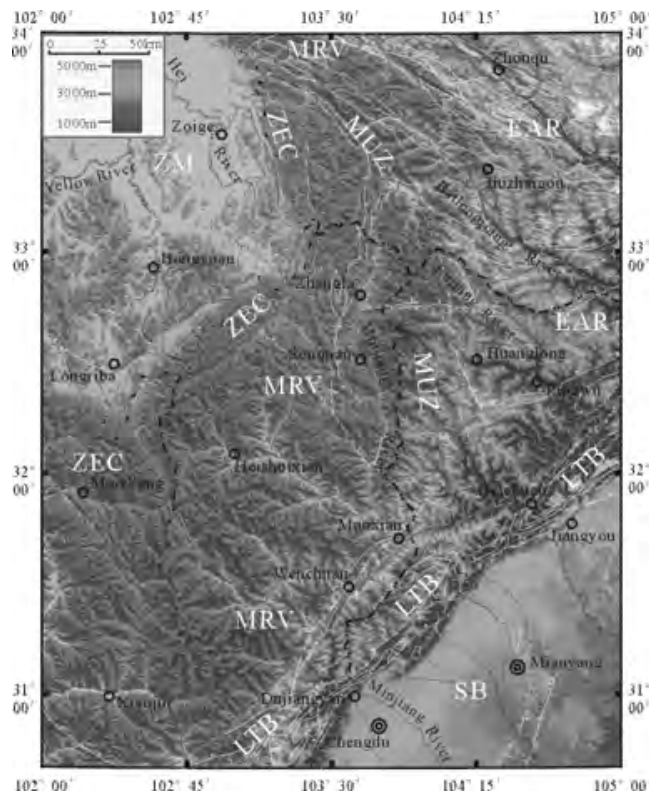

FIGURE 2. The elevation-shaded DEM of the MTB. The blue dashed lines are the boundaries of the geomorphic units. The white lines are the faults presented in Fig. 1. ZM: Zoige massif, ZEC: Zoige east margin range chains, MRV: Minjiang River valley, MUZ: Minshan Uplifting Zone, EAR: East actic region, LTB: Longmenshan Thrust Belt, SB: Sichuan Basin. 
and the folded zones bilaterally distributed westwards and eastwards of the uplifting zone. Accordingly, the MTB includes four geomorphic units as the ZEC, the MRV, the MUZ and the EAR (Figure 2). Although Kirby et al. $(2000,2002)$ and Yang et al. (2004, in press) have taken cognizance of the geomorphic features along the northeast margin of the Tibetan Plateau, some aspects are still undiscussed yet, such as the drainage pattern and the mutual relations among the lithology, the structure and the topography.

Based on the digital elevation model (DEM) created by digitizing topographic contours $(1: 2,50,000)$, this study aims to analyze the geomorphic characteristics of the MTB in detail. The spatial resolution of the data used is $50 \mathrm{mx} 50 \mathrm{~m}$, and the interval of contours is $100 \mathrm{~m}$. The standard error of the elevation data is less than $45 \mathrm{~m}$. Although the resolution of the DEM is a little modest, nevertheless, it is also useful for this study. Almost all of the procedures including visualization and data processing were done with the software MapGIS ${ }^{\mathrm{TM}} 6.5$ (Zondy InfoEngineering Co., Ltd.Wuhan, China).

Figure 2 shows the elevation shaded DEM overlain by the boundaries of an important contacts and the main and secondary water divides. In the northwestern flank of the study area, the elevation of the eastern Zoige massif controlled by the NE trending Longriba Fault is about 3500-3800 m, presenting itself in an annular shape. The low local relief of this region is very typical. The main drainage divide of the Huang He (Yellow River) and the Chang Jiang (Yangtze River) is about along the margin of the Zoige massif. The Hei River and other confluents flow generally north into the Yellow River, and the outcrops of the Mesozoic granites confine the drainages at the southeast. Eastward the plateau transits itself from $4000 \mathrm{~m}$ to $4500 \mathrm{~m}$ and reaches the Minjiang River Valley Zone at the elevation of about $1500-3800 \mathrm{~m}$. The Minjiang River is also N-S trending like the Hei River. But unlike the later, the Minjiang River flows south to the Yangtze River, which is mostly restricted by the Cenozoic activities of the Minjiang Fault Zone in the north and of the Longmenshan Tectonic Belt in the south (Zhao et al. 1994a, 1994b). The drainage style of the Minjiang River abstracted from the Figure 2 also can attract our attention. On the western side, there are plenty of developed confluents, and the drainage is very extensive. Meanwhile, the case on the east side of the Minjiang River is contrary to the west; there exists almost no tributaries. This drainage appearance magnificently confirms the differential uplifting of the east flank vs. the west side of the river.

Besides the above-mentioned, the most important and interesting geomorphic unit is the Minshan Uplift Zone; many studies indicate that the MUZ is clumped between the MFZ and the HF, and has experienced the intense Cenozoic tectonic uplifting (Zhou et al. 2000, Deng et al. 1994, Zhao et al. 1994b, Kirby et al. 2000). This uplifting zone is about $40-50 \mathrm{~km}$ wide and contains many peaks that are above $4500 \mathrm{~m}$ even reaching 5588 $\mathrm{m}$. Note that the higher erodibility and the outcropping altitude of the carbonatite along the uplift zone, we also can infer the intense differential uplifting of the MUZ during the Cenozoic. Based on the analysis of the dislocation elevation of the existing planation surface and the strata age, Zhou et al. (2000) estimated that the mean uplifting rate of the MUZ is about $1.5 \mathrm{~mm} / \mathrm{a}$ from the Quaternary, and also proposed the formation mechanism of the new rise of the Minshan block (the MUZ in our study). Southward, the MUZ joins up with the Longmenshan Tectonic Belt, and becomes an erosional escarpment adjacent to the Sichuan Basin. Together with the LTB, the topographic dominance of the MUZ makes them the northeast margin of the Tibetan Plateau.

In the east and northeast flanks of our study area, the landforms with an altitude of 1000-3000 m are members theWest Qingling Orogen. The gradient of this region is greater than any other part. Topographically, the E-W geomorphic difference becomes very well marked. The drainage patterns of the Bailongjiang River and the Fujiang River of Jialingjiang Drainage are regularly flowing in the directions of NNW or near EW, obviously differing from the other west drainages such as the Minjiang River and Hei River. This geomorphic appearance represents the tectonic stress transformation from EW to NW-SE regionally.

In conclusion, the Minshan Tectonic Belt, as the northeastern margin of the Tibetan Plateau, has distinct characteristics of topography, which are in relation to the structure and the stratigraphical lithology. The drainage divide of the Yellow River and the Yangtze River is controlled mainly because of the lithological difference; however, in the Yangtze River drainage, the differential uplifting during the Cenozoic controls the patterns of the drainage networks.

\section{References}

Zhao XL, QD Deng and SF Chen. 1994a. Tectonic geomorphology of the central segment of the Longmenshan Thrust Belt, west Sichuan, Southwestern China. Seismology and Geology 16(4): 422-428 (in Chinese with English abstract)

Zhao XL, QD Deng and SF Chen. 1994b. Tectonic geomorphology of the Minshan Uplift in the western Sichuan, Southwestern China. Seismology and Geology 16(4): 429-439 (in Chinese with English abstract)

Chen SF, CJL Wilson, QD Deng and others 1994. Active faulting and block movement associated with large earthquakes in the Min Shan and Longmen Mountains, northeastern Tibetan Plateau. J Geophys Res 99(12): 24,025-38

Burchfiel BC, Z Chen, Y Liu and others. 1995. Tectonics of the Longmen Shan and adjacent regions, central China. Int Geol Rev 37: 661-735

Kirby E, KX Whipple, BC Burchfiel and others 2000. Neotectonics of the Min Shan, China: Implications for mechanisms driving Quaternary deformation along the eastern margin of the Tibetan Plateau. GSA bulletin 112(3): 375-393 